\title{
Analysis of the Influence of Renewable Generator Frequency Endurance Capability on Low-Frequency Load Shedding: A Hunan Case Study
}

\author{
Yang-Wu Shen $\mathbb{D}^{1},{ }^{1}$ Ding Wang, ${ }^{1}$ Hao Chen, ${ }^{2}$ Jian Zuo, ${ }^{1}$ Min Xu, ${ }^{2}$ and Wei Cao ${ }^{2}$ \\ ${ }^{1}$ The State Grid Hunan Electric Power Company Limited Research Institute, Hunan, China \\ ${ }^{2}$ The State Grid Hunan Electric Power Company Limited, Hunan, China \\ Correspondence should be addressed to Yang-Wu Shen; shenyangwu@126.com
}

Received 19 August 2020; Revised 11 October 2020; Accepted 8 December 2020; Published 21 December 2020

Academic Editor: Qiang Chen

Copyright ( 92020 Yang-Wu Shen et al. This is an open access article distributed under the Creative Commons Attribution License, which permits unrestricted use, distribution, and reproduction in any medium, provided the original work is properly cited.

With the rapid development of renewable generators such as distributed photovoltaic and profound changes of the power structure, this paper analyzes the frequency characteristics of the power system with high penetration of renewable generations in the process of low-frequency load shedding and discusses the influence of the distributed renewable generator frequency endurance capabilities on the implementation effect of low-frequency load shedding in detail. Finally, the influences of the distributed renewable generator frequency endurance capability and the capacities of the distributed renewable generator on frequency response characteristics of an actual Hunan power grid are simulated. The simulation results show that more distributed photovoltaic capacity without frequency endurance capability leads to deeper frequency drops after the disturbance and requires more basic rounds of load shedding. When the penetration rate of distributed photovoltaic is too high, it may cause load shedding, resulting in power grid load losses and, at the same time, leading to an overshoot phenomenon in the process of frequency recovery. Therefore, the influence of distributed photovoltaic on the control of low-frequency load shedding should be considered when designing low-frequency load shedding schemes for the power grid with high penetration of distributed photovoltaic.

\section{Introduction}

The frequency of the power system reflects the balance between the active power generated by the system and the active power required by the load $[1,2]$. When there is a large active power shortage due to the fault, the frequency of the system will drop, and, in serious cases, it may cause the frequency collapse, resulting in a larger power outage. Low-frequency load shedding is an important part of the "third line of defense" [2], which is an effective measure to prevent frequency collapse and is widely used in power systems [3, 4]. However, as an important indicator to measure the safe and stable operation of the power system, the dynamic frequency characteristics of the power system become more complicated with the change of power grid structure [5-9].
At present, the low-frequency load shedding methods can be roughly put into four categories: the traditional load shedding method according to the turns, the adaptive lowfrequency load shedding method [10], the load shedding method using node information to constitute the index $[4,11,12]$, and the low-frequency load shedding method guided by artificial intelligence method [13]. How to reasonably arrange the low-frequency load shedding scheme while ensuring the security of the power grid with the minimum cost is a key problem. In [14], considering the load capacity constraints, total system load limits, and system steady-state frequency constraints, an optimization model of low-frequency load shedding limit was proposed. The experiments conducted showed that a large number of refrigerators can deliver frequency reserves approximately equal to their average power consumption. Electric space heaters can also provide frequency 
reserves of over $90 \%$ of their maximum power consumption in certain weather conditions. In [15], considering the importance of load and the sensitivity of load shedding to system frequency recovery, a new low-frequency load shedding optimization model was formulated. The frequency restoration is designed to use demand response as the first option to intercept frequency decline when a large disturbance occurs. Then, the scheduled spinning reserve is used to restore frequency back to the predisturbance level. Test results showed that the proposed spinning reserve and demand response deployment scheme could effectively restore frequency under various contingency conditions. In addition, based on the security of transient frequency offset, the study in [16] analyzed the influence of voltage, corrected the frequency offset, and optimized the load shedding amount of each turn in the traditional low-frequency load shedding scheme. Although the above-mentioned methods are effective, the actual production cost is high, and the engineering practicability is poor.

At present, most of the low-frequency load shedding schemes in the actual power grid adopt the traditional load shedding method according to the turn. In the process of power system frequency reduction caused by an accident, the load is cut off according to the sequence of different frequency setting values. With the changes of different energy proportion structures of the power grid, the adaptability of the traditional low-frequency load shedding parameter setting method has become worse $[17,18]$. When the proportion of hydropower in flood season is high, the overshedding phenomenon may appear in the load shedding device. According to the characteristics of different proportions of thermal power in different operation modes of the power grid in flood season and dry season and combined with the influence of hydropower on power grid frequency, this paper improves the traditional lowfrequency load shedding scheme to increase its adaptability. This method can also provide a reference for frequency stability control in areas with a high proportion of hydropower.

The contributions of this paper are summarized as follows: (1) this paper analyzes the frequency endurance capacity of the distributed photovoltaic generation in Hunan Province and its influences on the frequency response characteristic of the power system; (2) this paper analyzes the influence of the frequency endurance capability of the distributed photovoltaic generation on the low-frequency load shedding in Hunan power grid; and (3) this paper improves the traditional low-frequency load shedding scheme to increase its adaptability, which can provide a reference for frequency stability control in areas with a high proportion of hydropower.

\section{Introduction of the Distributed Photovoltaic Generation in Hunan Power Grid}

In recent years, with the progress of photovoltaic generation technology, the decrease of cost, and the support of relevant national policies, the distributed photovoltaic generation in Hunan province presents a high-speed development trend of "multiple points, wide range, and local high-density grid integration.” By May 2020, there are 506 distributed photovoltaic generation systems with a capacity of $2.16 \mathrm{MW}$ in
Hunan Province, of which 148 systems with a capacity of $1.36 \mathrm{MW}$ are connected with $10 \mathrm{kV}$ or higher voltage level power grids. In terms of regional distribution, the distributed photovoltaic generations in Hunan mainly locate in Changde, Yueyang, Hengyang, Changsha, and Yongzhou with a capacity of $1.54 \mathrm{MW}$, accounting for $71 \%$ of the provincial power grid capacity. The distributed photovoltaic distribution in Hunan Province is shown in Figure 1.

\section{Influence of Frequency Endurance of the Distributed Photovoltaic Generation on Load Shedding Control}

\subsection{Requirements for Frequency Endurance of the Distributed} Photovoltaic Generation. At present, relevant requirements on the frequency tolerance of the distributed photovoltaic generation are put forward in many national standards, among which the frequency operation range of the distributed photovoltaic generation is given in "technical requirements for grid integration of distributed generation" (GB/t33593-2017) [19] and "guidelines for security and stability of power system" (GB/38755-2019) [20].

"Technical requirements for grid integration of distributed generation" require that the distributed generation directly connected to the $10 \mathrm{kV}$ voltage level and $35 \mathrm{kV}$ voltage level power grids should have a certain ability to withstand system frequency abnormality and should be able to operate within the power grid frequency range according to regulations shown in Table 1.

The new version of "guidelines for security and stability of power system" has more stringent requirements on the frequency endurance capacity of the distributed photovoltaic generation. In principle, the frequency endurance capacity of distributed generation is consistent with that of synchronous generators. The frequency endurance capacity of the distributed generation shall meet the following requirements when it continuously operates in the range of $48.5 \sim 50.5 \mathrm{~Hz}$, as shown in Table 2 .

3.2. Investigation and Analysis on Frequency Endurance Capability of the Distributed Photovoltaic Generation in Hunan Power Grid. The research is conducted on 174 distributed photovoltaic systems in Changde, Yueyang, Hengyang, Changsha, and Yongzhou. 29 of them are $35 \mathrm{kV}$ distributed generation systems with a capacity of $684000 \mathrm{~kW}$, and 145 of them are $10 \mathrm{kV}$ or below systems with a capacity of $301700 \mathrm{~kW}$.

According to the statistical analysis, the frequency endurance capacities of 41 distributed photovoltaic units do not meet the frequency tolerance requirements stipulated in "technical requirements for grid integration of distributed generation" and the new version of "guidelines for security and stability of power system." The grid integration capacity is $51100 \mathrm{~kW}$, accounting for $5 \%$ of the photovoltaic capacity, including $535 \mathrm{kV}$-photovoltaic units with a capacity of $18400 \mathrm{~kW}$ and $3610 \mathrm{kV}$-photovoltaic units and $380 \mathrm{~V}$ photovoltaic units with a total capacity of $32700 \mathrm{~kW}$. The details are shown in Table 3. 


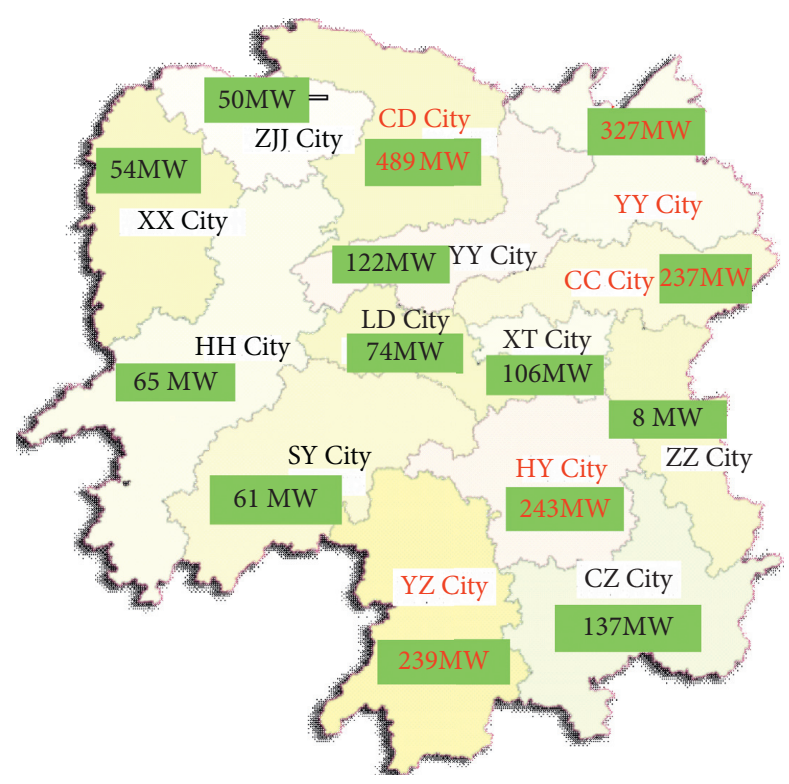

FIgURe 1: Distribution of the distributed photovoltaic generation in Hunan Province.

TABLE 1: Frequency response time requirements of distributed generation.

\begin{tabular}{|c|c|}
\hline $\begin{array}{l}\text { Frequency } \\
\text { range }\end{array}$ & Requirements \\
\hline $\mathrm{f}<48 \mathrm{~Hz}$ & $\begin{array}{l}\text { The type of converter is determined by the distributed generation according to the minimum allowable frequency of } \\
\text { the converter or the requirements of the grid dispatching organization }\end{array}$ \\
\hline $48 \mathrm{~Hz} \leq f<49.5 \mathrm{~Hz}$ & It is required to operate for at least $10 \mathrm{~min}$ each time when it is lower than $49.5 \mathrm{~Hz}$ \\
\hline $49.5 \mathrm{~Hz} \leq f<50.2 \mathrm{~Hz}$ & Continuous operation \\
\hline & $\begin{array}{l}\text { When the frequency is higher than } 50.2 \mathrm{~Hz} \text {, the distributed generation should have the ability to } \\
\text { reduce the active power output, and the actual operation can be decided by the power grid dispatching }\end{array}$ \\
\hline $50.2 \mathrm{~Hz}<f \leq 50.5 \mathrm{~Hz}$ & $\begin{array}{c}\text { organization; at this time, the distributed generation in the outage state is not allowed to be integrated into the } \\
\text { power grid }\end{array}$ \\
\hline $\mathrm{f}>50.5 \mathrm{~Hz}$ & $\begin{array}{l}\text { The power transmission to the grid line will be terminated immediately, and the grid integration of distributed } \\
\text { generation in the shutdown state is not allowed }\end{array}$ \\
\hline
\end{tabular}

TABLe 2: Allowable operation time of abnormal frequency.

\begin{tabular}{lcc}
\hline Frequency range $\mathrm{Hz}$ & Cumulative allowable running time min & Allowable running time per time sec \\
\hline $51.0 \sim 51.5$ & $>30$ & $>30$ \\
$50.5 \sim 51.0$ & $>180$ & $>180$ \\
$48.5 \sim 50.5$ & Continuous operation & $>300$ \\
$48.5 \sim 48.0$ & $>300$ & $>60$ \\
$48.0 \sim 47.5$ & $>60$ & $>20$ \\
$47.5 \sim 47.0$ & $>10$ & $>5$ \\
$47.0 \sim 46.5$ & $>2$ & \\
\hline
\end{tabular}

TABLE 3: Statistical analysis results of frequency endurance capability.

\begin{tabular}{|c|c|c|c|c|c|}
\hline $\begin{array}{l}\text { The type of distributed } \\
\text { photovoltaics }\end{array}$ & Amount & $\begin{array}{l}\text { Grid } \\
\text { integration } \\
\text { capacity }\end{array}$ & $\begin{array}{l}\text { Amount of frequency } \\
\text { resistant capacity not } \\
\text { up to standard }\end{array}$ & $\begin{array}{c}\text { Frequency endurance } \\
\text { capacity not up to } \\
\text { standard }\end{array}$ & $\begin{array}{c}\text { The proportion of capacity } \\
\text { with frequency endurance } \\
\text { not up to standard }\end{array}$ \\
\hline $\begin{array}{l}35 \mathrm{kV} \text { grid integration of the } \\
\text { distributed photovoltaic } \\
\text { generation }\end{array}$ & 29 & 68.4 & (r) & 1.84 & 2.69 \\
\hline $\begin{array}{l}10 \mathrm{kV} \text { and below grid } \\
\text { integration of the distributed } \\
\text { photovoltaic generation }\end{array}$ & 145 & 30.17 & 36 & 3.27 & 10.84 \\
\hline Total & 174 & 98.57 & 41 & 5.11 & 5.18 \\
\hline
\end{tabular}




\section{Influence of Frequency Endurance Capacity of the Distributed Photovoltaic Generation on Load Shedding Control in Hunan Province}

4.1. Frequency Characteristics in the Process of Low-Frequency Load Shedding. In order to simplify the theoretical analysis of low-frequency load shedding, the traditional equivalent single machine with load frequency response model block diagram shown in Figure 2 is used for theoretical analysis. The forward link in Figure 2 represents the rotor rotation equation of the equivalent generator, and two feedback links represent the load and frequency characteristics of the generator.

According to Figure 2, the state equation of the system can be listed as

$$
\left\{\begin{array}{l}
T_{S} \frac{\mathrm{d} \Delta f}{\mathrm{~d} t}=-\Delta P_{\mathrm{OL}}, \\
T_{G} \frac{\mathrm{d} \Delta P_{G}}{\mathrm{~d} t}+\Delta P_{G}=-K_{G} \Delta f \\
\Delta P_{D}=K_{D} \Delta f \\
\Delta P_{\mathrm{OL}}=\Delta P_{D}-\Delta P_{G}+\Delta P_{\mathrm{OLO}}
\end{array}\right.
$$

where $\Delta P_{L}$ is the frequency regulation effect of the load, $\Delta P_{G}$ is the primary frequency regulation measure for generating units. $T_{S}$ is the inertia time constant of the equivalent machine; $\Delta P_{O L}$ is the power shortage after the joint action of the unit and the load; $T_{G}$ is the comprehensive time constant of the governor and prime mover of the generator; $K_{G}$ is the static characteristic power-frequency coefficient of the generator; $\Delta P_{D}$ is the power of the frequency regulation effect of the load; $K_{D}$ is the frequency regulation effect coefficient of the system load; and $\Delta P_{\text {OLO }}$ is the power deficit caused by the disturbance.

It can be seen from equation (1) that when the frequency dynamic process of the equivalent single machine system shown in Figure 3 is an attenuated oscillation curve, the descending speed of frequency is directly proportional to the power shortage, and the slope of frequency decline can be expressed as

$$
\frac{\mathrm{d} \Delta f}{\mathrm{~d} t}=-\frac{\Delta P_{\mathrm{OLO}}}{T_{S}} .
$$

Due to the influence of the governor and the load frequency factor, the power deficit $\Delta \mathrm{P}_{\mathrm{OLO}}$ of the system decreases with the decrease of frequency in the process of the disturbance. The frequency of the power system is a curve with the slope decreasing over time after the disturbance. After the action of low-frequency load shedding, the power vacancy $\Delta P_{\text {OLO }}$ decreases and the frequency decrease speed slows down. Under the joint action of the governor and the low-frequency load shedding device, the system frequency can be restored.

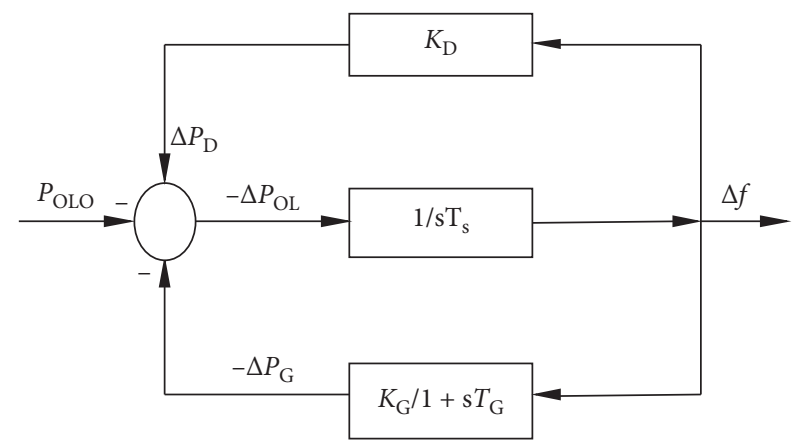

FIGURE 2: Block diagram of frequency response model of an equivalent single machine with load.

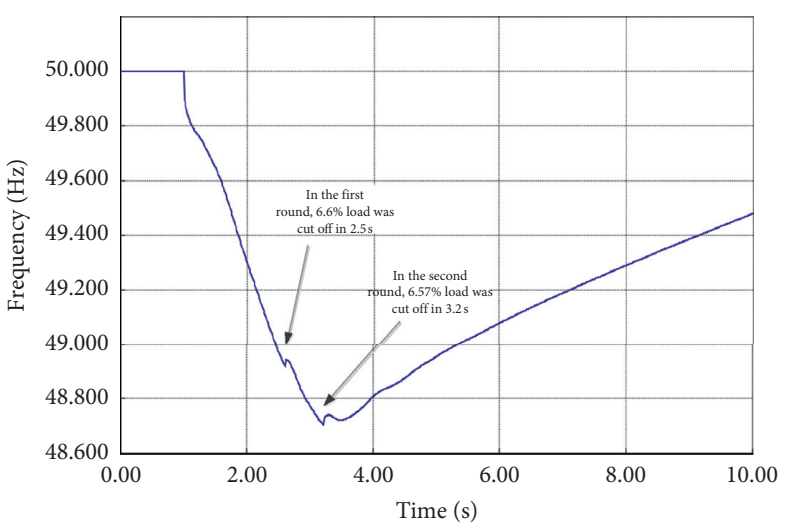

FIGURE 3: Frequency characteristic curve after low-frequency load shedding.

As shown in Figure 3, in case of a disturbance in the power system, $6 \%$ of the total system load before the fault is cut off at $2.59 \mathrm{~s}$ and $3.2 \mathrm{~s}$, respectively, and the slope of system frequency changes every time the load is cut off. Under the joint action of the low-frequency load shedding device and the unit governor, the frequency finally returns to a new balance point.

In the dynamic frequency response process, the unit regulation coefficient of load and the unit regulation coefficient and inertia constant of the generator are the key indexes. For the multimachine system, the unit value of the equivalent regulation coefficient is

$$
K_{G}^{*}=\frac{\sum_{i=1}^{n} K_{G i} \cdot P_{G i N}}{P_{G N}}
$$

where $P_{G i N}$ is the rated power of the $i$-th generation unit and $P_{G N}=\sum_{i=1}^{n} P_{G i N}$ is the sum of the rated power of $N$ generation units in the whole system. The unit value of the equivalent regulation coefficient of the loads is

$$
K_{L \sum^{*}}=\frac{\sum_{i=1}^{n} K_{L i} \cdot P_{L i N}}{P_{L N}} .
$$

The unit value of the regulation coefficient of the power system is 


$$
K_{S^{*}}=\rho K_{G}^{*}+K_{L}^{*} \sum^{*}
$$

In the calculation of $K_{\mathrm{G}}$, if the $j$-th generation unit has been in full operation, $K_{G j}=0$ when the load increases. $\rho=$ $P_{G N} / P_{D N}$ is the reserve coefficient of the power system, and it is also the ratio of the rated capacity of the generation units to the total active power of loads.

Inertia constant $T_{J} \sum$ of the generation unit is an important parameter reflecting the mechanical inertia of the generator rotor. If several generators are combined into one equivalent generator, the total generation of the whole system is $S_{B}$; then, the unit value of inertia constant of the generator unit is

$$
T_{J} \sum=\frac{\sum_{i=1}^{n} T_{J N i} S_{N i}}{S_{B}} .
$$

It is approximately considered that the inertia constant $T_{J} \sum$ of the generator unit is the inertia constant $M_{S}$ of the power system.

4.2. Influence of Frequency Endurance Capability of the Distributed Photovoltaic Generation on Frequency Characteristics of Power System. The frequency of the power system reflects the balance between the active power generation and active power consumption. When the larger active power vacancies occur due to faults, the frequency will decrease, which may cause frequency collapse of the system and cause large-scale blackouts. Low-frequency load shedding is an important part of the "third line of defense" and an effective measure to prevent system frequency collapse. However, as an important index to measure the safe and stable operation of the power system, the dynamic frequency characteristics of the power system become more complicated with the large-scale distributed photovoltaic and other new energy sources.

The frequency endurance capability of the distributed photovoltaic refers to the ability to maintain continuous operation when the system frequency exceeds the normal range. Stipulated in "technical requirements for grid integration of distributed generation," when the frequency fluctuates in the range of $49.5 \mathrm{~Hz}-50.2 \mathrm{~Hz}$, the distributed photovoltaic generation should keep continuous operation; when the frequency fluctuates from $48 \mathrm{~Hz}$ to $49.5 \mathrm{~Hz}$, the distributed photovoltaic should operate for at least 10 minutes. When the frequency drops to $49.45 \mathrm{~Hz}$ due to power shortage, if the distributed photovoltaic does not have the low-frequency endurance ability, the distributed photovoltaic will be offline, resulting in large-scale power shortage and eventually deteriorating the frequency response characteristics of the power system.

Most of the low-frequency load shedding methods in the actual power grid adopt traditional load shedding according to the turn. During power system frequency reduction caused by an accident, the load is cut off according to the sequence of different frequency setting values. Table 4 shows the low-frequency load shedding scheme of the Hunan power grid.
The basic turn is composed of five basic turns, the basic turn level difference is $0.25 \mathrm{~Hz}$, the exit delay is 0.15 seconds, the action frequency of the five basic turns is $49 \mathrm{~Hz}$, $48.75 \mathrm{~Hz}, 48.5 \mathrm{~Hz}, 48.25 \mathrm{~Hz}$, and $48 \mathrm{~Hz}$ respectively, and the load shedding amount of the first turn is $6.6 \%$. The load shedding of the second and fourth rounds was $6.57 \%$. The action frequency of special turns I-III is $49.25 \mathrm{~Hz}$, and the exit delay is 10 seconds, 15 seconds, and 20 seconds, respectively.

In the regional power system with high penetration of distributed photovoltaic generations, if a large-scale off-grid accident occurs due to poor frequency endurance capacity of distributed photovoltaic, the power shortage will be further extended. Since the traditional low-frequency load shedding scheme does not consider the influence of distributed photovoltaic frequency endurance capacity, the load shedding amount designed in the scheme is less than the actual power deficit, resulting in the undercutting phenomenon of low-frequency load shedding load. As a result, the total power deficit $\Delta \mathrm{P}_{\mathrm{OLO}}$ of the power system increases. According to (2), the decrease speed of the frequency will be accelerated, which will cause the lowest point of the frequency to decrease in the process of the disturbance.

\section{Case Study}

In order to analyze the influence of the distributed photovoltaic frequency endurance capability on the implementation effect of low-frequency load shedding in detail, a real-time hardware in the loop (HIL) system from ModelingTech [21] is built as shown in Figure 4, which includes a StarSim software, a real-time simulator (NI FPGA board $7868 \mathrm{R}$ ), and a rapid control prototype (PXIe 8821 controller). The simulation data is obtained from operations of the second half of 2020 issued by the national dispatching center of China. The total load is $18.16 \mathrm{GW}$, the capacity of the distributed photovoltaic generation is $2.16 \mathrm{GW}$, the integration capacity of direct current power transmission in Qishao is $800 \mathrm{MW}$, the capacity of Hubei-Hunan connecting line is $2.87 \mathrm{GW}, 14$ thermal power units are in operation, and $18 \%$ rotating reserve capacity is reserved. In the simulation process, the distributed photovoltaic generation is switched off according to the frequency change caused by the lack of frequency endurance.

5.1. Influence of Frequency Endurance Capability of the Distributed Photovoltaic Generation on Load Shedding Control of Hunan Power Grid. According to the statistics in the second section, the grid integration capacity of the distributed photovoltaic generation in Hunan Province, which does not meet the frequency endurance requirements of "technical requirements for grid integration of distributed generation" and the new version of "guidelines for security and stability of power system", accounts for $5.18 \%$ of the total capacity. Therefore, the two following cases are conducted:

A1: all distributed photovoltaic systems are frequency tolerant. 
TABLE 4: Statistical analysis results of frequency endurance capability.

\begin{tabular}{lccccccc}
\hline \multirow{2}{*}{ Round of actions } & \multicolumn{3}{c}{ Foundation turn } & \multicolumn{3}{c}{ Special turn } \\
& I & II & III & IV & V & I & II \\
\hline Action frequency (Hz) & 49 & 48.75 & 48.5 & 48.25 & 48 & 49.25 & 49.25 \\
Action delay (s) & 0.15 & 0.15 & 0.15 & 0.15 & 0.15 & 10 & 15 \\
Load reduction ratio at each level (\%) & 6.6 & 6.57 & 6.57 & 6.57 & 6.57 & 2.39 & 2.39 \\
\hline
\end{tabular}

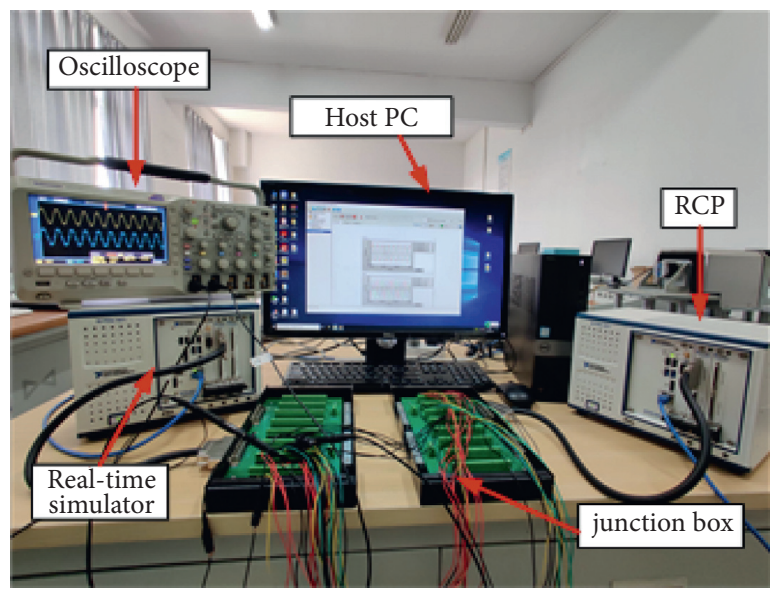

FIgURE 4: RCP and HIP simulation platform.

B1: $5 \%$ of the distributed photovoltaic generation capacity does not have frequency endurance ability.

In the above two cases, the Er-Xaing tie line (Gegang line and LianL-double circuit line) experiences line fault tripping. The frequency control is carried out according to the low-frequency load shedding scheme shown in Table 4 . The frequency dynamic response characteristic curve is shown in Figure 5. The blue curve is the frequency response characteristic in A1, and the green curve is the frequency response characteristic in B1.

It can be seen from Figure 4 that, at a penetration rate of $12 \%$ for the distributed photovoltaic generation, the power system can return to the new steady-state operation point after two rounds of load shedding. During the first round of load shedding, $1.2167 \mathrm{GW}$ of the load is cut off, while only $11000 \mathrm{~kW}$ of the distributed photovoltaic generation is offgrid under the B1 case, which is smaller compared with the first round of load shedding. According to (2), the system frequency decline rate has a small change. Moreover, the system frequency drops rapidly, and the time duration to start the second round of load shedding is short, so the minimum frequency difference between the two modes is not significant. After the second round of load shedding, the frequency recovery speed in B1 is slower than that in A1, which is mainly because the frequency rise rate in $\mathrm{B} 1$ is smaller than that in A1 after two rounds of load shedding.

5.2. Influence of the Distributed Photovoltaic Generation with Different Capacities without Frequency Endurance on Load Shedding Control of Hunan Power Grid. In order to further compare the influence of frequency endurance capability of the distributed photovoltaic generation on the load shedding control of the Hunan power grid, the following two cases are considered:

C1: considering that $25 \%$ of the capacity of the distributed photovoltaic generation does not have the frequency endurance capability.

D1: considering that $50 \%$ of the capacity of the distributed photovoltaic generation does not have the ability of frequency endurance.

Using the disturbance and low-frequency load shedding scheme mentioned above, the dynamic frequency response characteristic curves in four cases are shown in Figure 5, in which the red curve is the frequency response characteristic in $\mathrm{C} 1$ and the cyan curve is the frequency response characteristic in D1. The frequency characteristic indexes are shown in Table 5.

It can be seen from Figure 6 that the power system only needs two basic rounds of load shedding in B1 and $\mathrm{C} 1$, and the frequency can be recovered to the new balanced point. However, the system needs three load shedding basic rounds in D1. The main reason is that the higher proportion of the off-grid distributed photovoltaic generation leads to a greater power shortage of the system. Thus, more loads are cut off to maintain the active power balance in the power system. At the same time, if more distributed photovoltaic generations do not have frequency tolerance capabilities, the frequency drops faster and the minimum frequency is smaller. As can be seen from Figure 4, the minimum frequencies are $48.72 \mathrm{~Hz}, 48.64 \mathrm{~Hz}$, and $48.52 \mathrm{~Hz}$, respectively, in B1, C1, and D1, as shown in Table 5. 


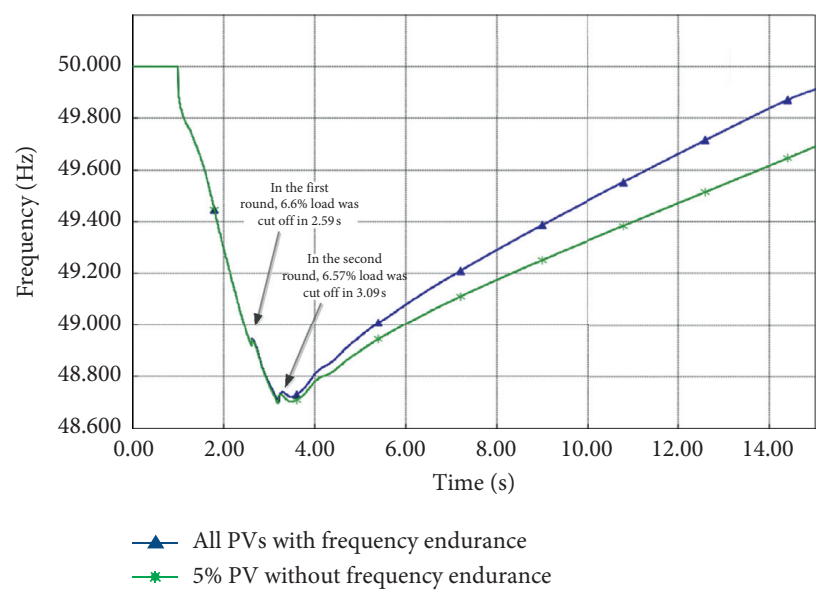

FIGURE 5: Influence of frequency endurance capability of the distributed photovoltaic generation on low-frequency load shedding control effect.

TABLE 5: Low-frequency load shedding scheme of Hunan power grid.

\begin{tabular}{|c|c|c|c|}
\hline $\begin{array}{l}\text { Proportion of the distributed photovoltaic generation without } \\
\text { frequency endurance capability (\%) }\end{array}$ & $\begin{array}{l}\text { Rounds of load that is } \\
\text { cut off }\end{array}$ & $\begin{array}{l}\text { Minimum } \\
\text { frequency }\end{array}$ & $\begin{array}{l}\text { Percentage of load } \\
\text { cutoff }\end{array}$ \\
\hline 0 & 2 & 48.72 & 13.17 \\
\hline 5 & 2 & 48.72 & 13.17 \\
\hline 25 & 2 & 48.64 & 13.17 \\
\hline 50 & 3 & 48.52 & 19.74 \\
\hline
\end{tabular}

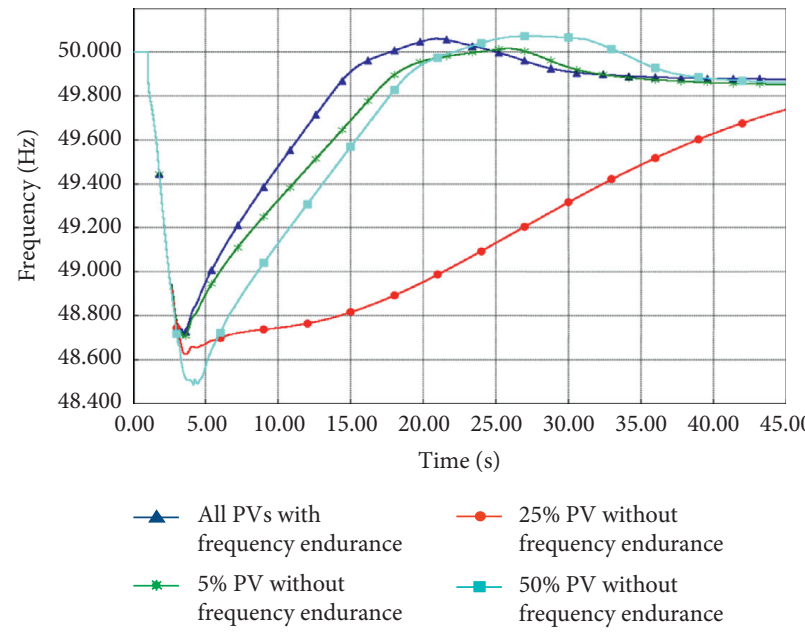

(a)

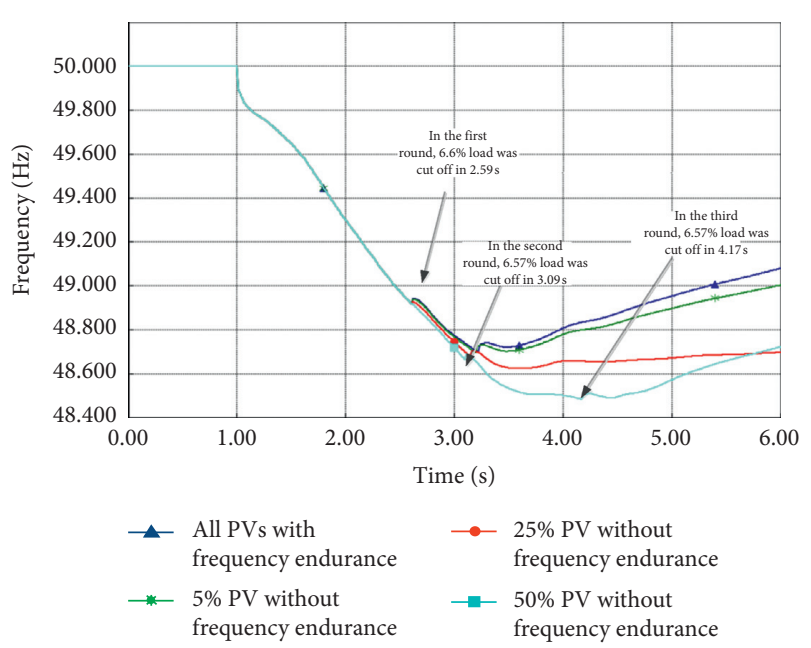

(b)

FIGURE 6: Frequency response of power system when the distributed photovoltaic generation without frequency endurance capability in different proportions: (a) The dynamic diagram of the whole process and (b) the partial enlarged drawing.

\subsection{Influences of Different Penetration Rates of the Distributed} Photovoltaic Generation on Load Shedding Control Quantity of Hunan Power Grid. In order to analyze the influence of the distributed photovoltaic penetration rate on the load shedding control quantity in the Hunan power grid, three operation scenarios with penetration rates of $10 \%, 20 \%$, and $30 \%$ are conducted. Under different penetration scenarios, the power shortage is simulated by tripping the
Hubei-Hunan tie line. Figures 7 and 8, respectively, show frequency dynamic response characteristic curves under two scenarios when all the distributed photovoltaic generations with the frequency endurance capabilities and 15\% of them without the the frequency endurance capabilities.

It can be seen from Figure 7 that when the penetration rate is $30 \%$, even if all the distributed photovoltaic generations have the frequency endurance capabilities according 


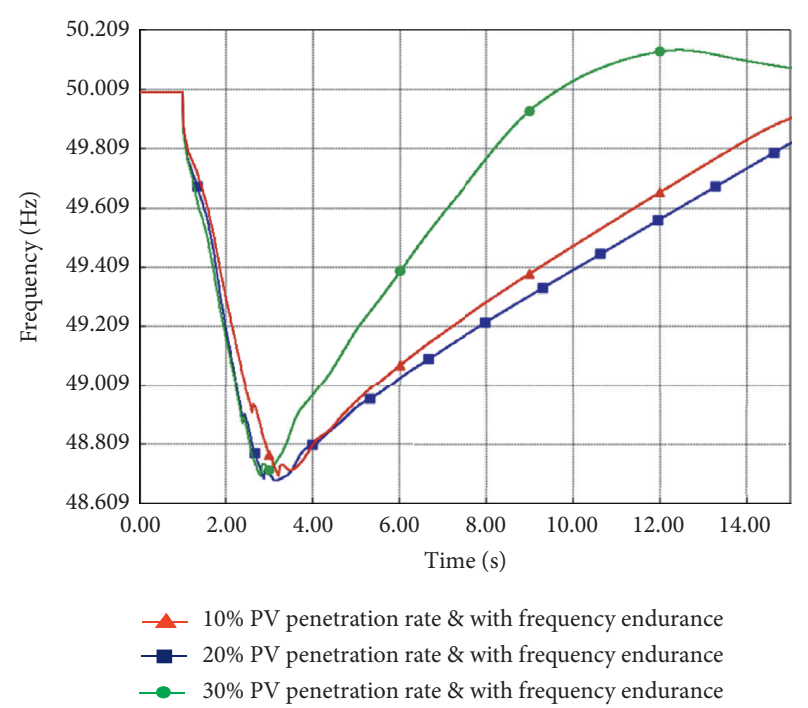

FIGURE 7: Frequency response under different penetration rates when all the distributed photovoltaic generations have frequency endurance capabilities.

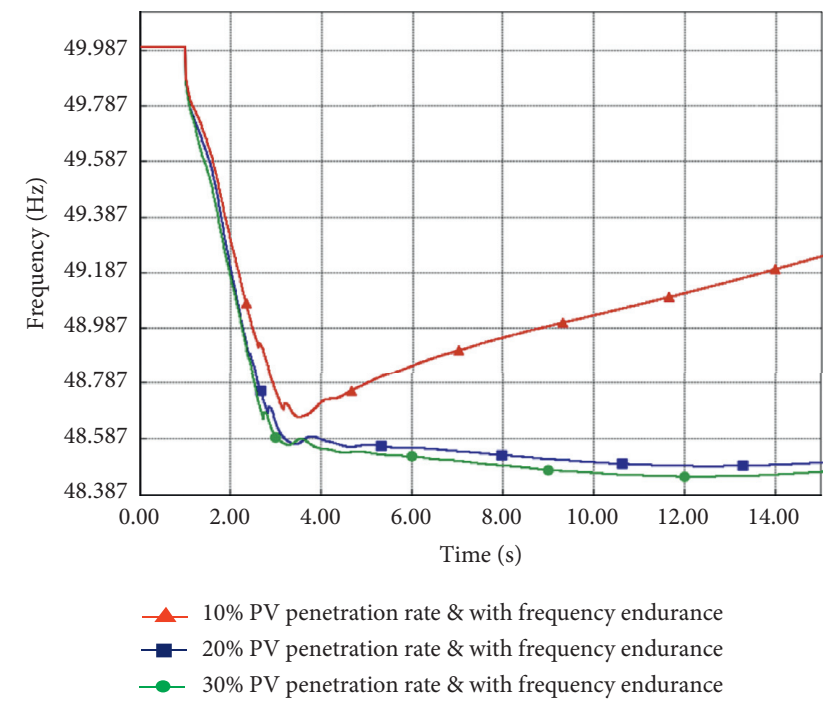

Figure 8: Frequency response of the power system with $15 \%$ the distributed photovoltaic generation with frequency endurance capability under different permeability.

to the traditional low-frequency load shedding control scheme, the frequency will overshoot in the recovery process due to the second round of overcutting. The traditional lowfrequency load shedding scheme does not consider the permeability of the distributed photovoltaic generation. When the permeability is high, the obtained load shedding amount may be greater than the actual required load shedding amount, resulting in the economic loss of the power system.

It can be seen from Figure 8 that when $15 \%$ of the distributed photovoltaic generations do not have the frequency endurance capabilities, the larger penetration ratio of the distributed photovoltaic generation leads to slower frequency recovery speed in the traditional low-frequency load shedding control scheme, which may trigger the special turn of low-frequency load shedding, consequently resulting in further load shedding. Therefore, the influence of the distributed photovoltaic generation on the control quantity of low-frequency load shedding needs to be considered when designing the low-frequency load shedding scheme for power systems with the high penetration of the distributed photovoltaic generation.

\section{Conclusion}

This paper analyzes the frequency endurance capacity of the distributed photovoltaic generation in Hunan Province and its influences on the frequency response characteristic of the power system. Finally, this paper analyzes the influence of the frequency endurance capability of the distributed photovoltaic generation on the low-frequency load shedding in the Hunan power grid. The conclusions are as follows:

(1) The lack of frequency endurance capability of the distributed photovoltaic generation will worsen power shortage during the disturbance, which will cause the low-frequency load shedding device to be prone to under load shedding, thus resulting in frequency decline rate increase during the disturbance and further reduction of the minimum frequency.

(2) During the frequency rising period, the distributed photovoltaic generation without the frequency endurance capability will slow down the frequency recovery speed.

(3) The simulation results show that the more the distributed photovoltaic generation without the heat resistance capability is, the deeper the frequency drops after the disturbance and the more basic rounds of load shedding are required. When the penetration rate of the distributed photovoltaic generation is too high, it may cause load shedding resulting in load loss and at the same time the overshoot phenomenon in the process of frequency recovery.

\section{Nomenclature}

$\Delta P_{\mathrm{L}}: \quad$ Frequency regulation effect of the load

$\Delta P_{\mathrm{G}}: \quad$ Primary frequency regulation measure of generating unit

$\Delta P_{\mathrm{OL}}: \quad$ Power shortage after the joint action of the unit and load

$\Delta P_{\mathrm{D}}: \quad$ Power of the frequency regulation effect of the load

$\Delta P_{\text {OLO }}$ : Power deficit caused by the disturbance

$\Delta T_{\mathrm{G}}: \quad$ Comprehensive time constant of the governor and prime mover

$K_{\mathrm{G}}: \quad$ Static characteristic power-frequency coefficient of the generator

$K_{\mathrm{D}}$ : $\quad$ Frequency regulation effect coefficient of the system

$P_{\mathrm{GiN}}: \quad$ Rated power of the $i$-th generation unit

$P_{\mathrm{GN}}: \quad$ Sum of the rated power of $N$ generation 


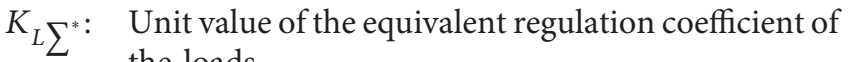
the loads

$K_{S^{*}}$ : Unit value of the regulation coefficient of power system

$T_{J}:$ Inertia constant of the generation unit

$S_{B}: \quad$ Total generation of the whole system

$\rho: \quad$ Reserve coefficient of power system

$K_{L i}: \quad$ Regulation coefficient of $i$-th load

$P_{L i N}: \quad$ The power of $i$-th load.

\section{Data Availability}

The data used to support the findings of this study are available from the corresponding author upon request.

\section{Conflicts of Interest}

The authors declare that there are no conflicts of interest regarding the publication of this paper.

\section{Acknowledgments}

This study was financially supported by the Science and Technology Project of State Grid Hunan Electric Power Company Limited (no. 5216A520000M).

\section{References}

[1] S. Yuan, D. Chen, T. Chen et al., "Coordinated control of multi-HVDC participating in three defense line at the receiving end of the power system with strong DC and weak AC," Electric Power, vol. 51, no. 10, pp. 72-79, 2018.

[2] Y.-W. Shen, D.-P. Ke, W. Qiao, Y.-Z. Sun, D. S. Kirschen, and C. Wei, "Transient reconfiguration and coordinated control for power converters to enhance the LVRT of a DFIG wind turbine with an energy storage device," IEEE Transactions on Energy Conversion, vol. 30, no. 4, pp. 1679-1690, 2015.

[3] G. Cai, Z. Sun, Y. Wang et al., "Optimization of under frequency load shedding scheme based on improved systemfrequency response model," Power System Technology, vol. 37, no. 11, pp. 3131-3136, 2013.

[4] Z. Song, J. Liu, Y. Liu et al., "WAMS-based adaptive UFLS considering dynamic correction," Electric Power Automation Equipment, vol. 34, no. 4, pp. 95-100, 2014.

[5] X. Ren, W. Li, Y. Xue et al., "Unstable modes evolution and its influencing factors analysis in interconnected power grids," Automation of Electric Power Systems, vol. 37, no. 21, pp. 9-16, 2013.

[6] Y. W. Shen, D. Wang, X. T. Deng, Q. Li, J. Zuo, and Z. K. Shuai, "Harmonic Modeling and Experimental Validation of the Converters of DFIGURE Based Wind Generation System," Complexity, vol. 2019, Article ID 7968914, 13 pages, 2019.

[7] Y. He, L. Guan, C. Qi et al., "Analysis of securing function and economic benefit of pumped storage station in power grid," Power System Technology, vol. 28, no. 20, pp. 54-67, 2004.

[8] A. Ketabi and M. H. Fini, "An underfrequency load shedding scheme for hybrid and multiarea power systems," IEEE Transactions on Smart Grid, vol. 6, no. 1, pp. 82-91, 2015.

[9] Y. Shen, L. Liang, M. Cui, F. Shen, B. Zhang, and T. Cui, "Advanced control of DFIGURE to enhance the transient voltage support capability," Journal of Energy Engineering, vol. 144, no. 2, Article ID 04018009, 2018.

[10] J. He, D. Bai, X. Wang et al., "An optimal algorithm of comprehensive cost for under-frequency loadshedding," Power System Technology, vol. 37, no. 12, pp. 3461-3466, 2013.

[11] Yi Tang, K. Deng, H. Sun et al., "Research on coordination scheme for smart household appliances participating under frequency load shedding," Power System Technology, vol. 37, no. 10, pp. 2861-2867, 2013.

[12] U. Rudez and R. Mihalic, "Monitoring the first frequency derivative to improve adaptive underfrequency load-shedding schemes," IEEE Transaction on Power System, vol. 26, no. 2, pp. 836-846, 2011.

[13] S. Padrón, M. Hernández, and A. Falcón, "Reducing underfrequency load shedding in isolated power systems using neural networks. Gran canaria: a case study," IEEE Transactions on Power Systems, vol. 31, no. 1, pp. 63-71, 2016.

[14] P. J. Douglass, R. Garcia, P. Nyeng et al., "Smart demand for frequency regulation experimental results," IEEE Transactions on Smart Grid, vol. 4, no. 3, pp. 1713-1720, 2013.

[15] L.-R. Chang-Chien, L. N. An, T.-W. Lin, and W.-J. Lee, "Incorporating demand response with spinning reserve to realize an adaptive frequency restoration plan for system contingencies," IEEE Transactions on Smart Grid, vol. 3, no. 3, pp. 1145-1153, 2012.

[16] Y.-W. Shen, D.-P. Ke, Y.-Z. Sun, D. S. Kirschen, W. Qiao, and X.-T. Deng, "Advanced auxiliary control of an energy storage device for transient voltage support of a doubly fed induction generator," IEEE Transactions on Sustainable Energy, vol. 7, no. 1, pp. 63-76, 2016.

[17] A. Annamraju and SrikanthNandiraju, "Robust frequency control in a renewable penetrated power system: an adaptive fractional order-fuzzy approach," Protection and Control of Modern Power Systems, vol. 4, no. 3, pp. 181-195, 2019.

[18] A. Annamraju and S. Nandiraju, "Coordinated control of conventional power sources and PHEVs using jaya algorithm optimized PID controller for frequency control of a renewable penetrated power system," Protection and Control of Modern Power Systems, vol. 4, no. 3, pp. 343-355, 2019.

[19] Technical requirements for grid connection of distributed resources https://www.chinesestandard.net/PDF.aspx/GBT335932017.

[20] Code on Security and Stability for Power System https://www. chinesestandard.net/PDF/English.aspx/GB38755-2019.

[21] Y. W. Shen, J. R. Yuan, F. F. Shen, J. Z. Xu, C. K. Li, and D. Wang, "Finite Control Set Model Predictive Control for Complex Energy System with Large-Scale Wind Power," Complexity, vol. 2019, Article ID 4358958, 13 pages, 2019. 